See Article page 190.

\section{Commentary: The dye don't lie, but does it tell the complete story?}

\author{
Joseph C. Cleveland, Jr, MD
}

\begin{abstract}
"The dye don't lie" is a favorite phrase of many interventional cardiologists and cardiovascular surgeons. Given the appropriate clinical circumstances, coronary angiography is the reference standard for the diagnosis and management of ischemic heart disease. ${ }^{1}$ But when is it not helpful in clinical decision making?

In this issue of The Journal of Thoracic and Cardiovascular Surgery Techniques, Winters and Halkos ${ }^{2}$ describe a case in which completion coronary angiography after coronary artery bypass grafting yielded an unexpected result. However, when one considers the totality of the clinical picture, perhaps the result was not so surprising.

The case involved a robotically assisted off-pump coronary artery bypass grafting with a left internal mammary artery (LIMA) graft placed to a small, chronically occluded left anterior descending (LAD). Although at the conclusion of the procedure, the patient exhibited no signs of myocardial ischemia or infarction, the findings from a "completion" angiogram suggested a poor technical result. Flow from the LIMA was only into a septal cascade/diagonal territory, with no antegrade or retrograde filling of the LAD.

The authors exhibited remarkably good judgment and did not reintervene on this bypass graft because the patient was clinically without signs of ischemia and the target vessel was small. I infer that a better bypass graft could not have been constructed on a second go-around. The key takeaway from this case is that without evidence of anterior wall
\end{abstract}

\footnotetext{
From the Division of Cardiothoracic Surgery, Department of Surgery, University of Colorado Anschutz Medical Center, Aurora, Colo.

Disclosures: The author reported no conflicts of interest.

The Journal policy requires editors and reviewers to disclose conflicts of interest and to decline handling or reviewing manuscripts for which they may have a conflict of interest. The editors and reviewers of this article have no conflicts of interest.

Received for publication March 22, 2020; revisions received March 22, 2020; accepted for publication March 27, 2020; available ahead of print April 11, 2020. Address for reprints: Joseph C. Cleveland, Jr, MD, Division of Cardiothoracic Surgery, Department of Surgery, University of Colorado Anschutz Medical Center, 12631 East 17th Ave, Building A01, Room 6602, MS C-310, Aurora, CO 80045 (E-mail: joseph.cleveland@ucdenver.edu).

JTCVS Techniques 2020;3:196-7

2666-2507

Copyright (C) 2020 The Authors. Published by Elsevier Inc. on behalf of The American Association for Thoracic Surgery. This is an open access article under the CC BY-NCND license (http://creativecommons.org/licenses/by-nc-nd/4.0/).

https://doi.org/10.1016/j.xjtc.2020.03.037
}

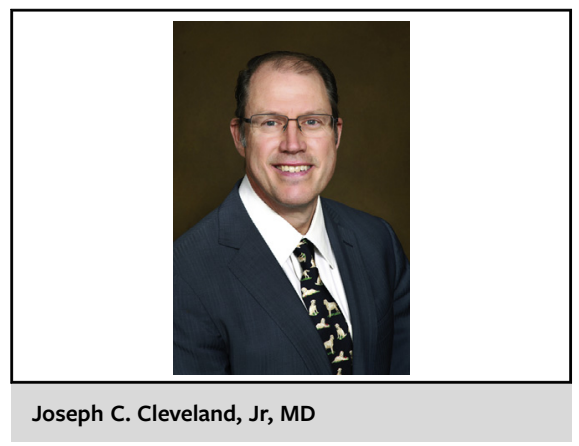

CENTRAL MESSAGE

Reintervention on a coronary artery bypass graft based solely on completion angiography is not always indicated.

ischemia, expectant management is a reasonable approach. One must not always revise such bypass grafts with poor outflow and a small target artery.

The story continues. At 1 year postoperatively, the patient underwent another coronary angiogram to "clear" him for spine surgery. This angiogram revealed that the LIMA to LAD bypass graft was now nicely patent. This follow-up angiogram illustrates that the LIMA to LAD relationship really is special. However, the pictures do not tell the complete story.

The fact that all may turn out well for the patient is evident by what the patient reports in this case. The patient reported that his anginal symptoms had resolved, and after recovery from surgery, he could engage in activities without experiencing symptoms of angina. Although these 2 sets of coronary angiograms suggest a very unusual outcome-a poorly functioning graft showing later patency-the patient's symptoms are entirely consistent with a functional LIMA to LAD graft.

"The dye don't lie" suggests that, when appropriate, coronary angiography can diagnose and offer intervention for ischemic heart disease. However, the outcome and symptom status of our patients will always tell the most complete story. Pictures of blood vessels alone are merely imagesour patients are the full picture.

\section{References}

1. Fihn SD, Gardin JM, Abrams J, Berra K, Blankenship JC, Dallas AP, et al. 2012 ACCF/AHA/ACP/AATS/PCNA/SCAI/STS guideline for the diagnosis and management of patients with stable ischemic heart disease: a report of the American College of Cardiology Foundation/American Heart Association task force on, American Association for Thoracic Surgery, Preventive 
Cardiovascular Nurses Association, Society for Cardiovascular Angiography and Interventions, and Society of Thoracic Surgeons. J Am Coll Cardiol. 2012;60:e44-164.
2. Winters AA, Halkos ME. To intervene or not intervene: lessons learned from completion angiography after robotic-assisted coronary bypass surgery. J Thorac Cardiovasc Surg Tech. 2020;3:190-3. 